\title{
A power primer
}

\author{
Jacob Cohen \\ New York University
}

One possible reason for the continued neglect of statistical power analysis in research in the behavioral sciences is the inaccessibility of or difficulty with the standard material. A convenient, although not comprehensive, presentation of required sample sizes is provided. Effect-size indexes and conventional values for these are given for operationally defined small, medium, and large effects. The sample sizes necessary for .80 power to detect effects at these levels are tabled for 8 standard statistical tests: (1) the difference between independent means, (2) the significance of a product-moment correlation, (3) the difference between independent rs, (4) the sign test, (5) the difference between independent proportions, (6) chi-square tests for goodness of fit and contingency tables, (7) 1-way analysis of variance (ANOVA), and (8) the significance of a multiple or multiple partial correlation.

From Psychological Bulletin (1992), vol 112(1), p. 155-159 . Copyright (C) 1992 by the American Psychological Association. Reproduced with permission. For information on how to obtain the full text to this article, please visit http://www.apa.org/psycarticles . 